\title{
Age-related changes of the multidrug resistance P-glycoprotein function in normal human peripheral blood $\mathrm{T}$ lymphocytes
}

C.G. Machado ${ }^{1,2}$, R.T. Calado ${ }^{1}$,

A.B. Garcia ${ }^{1}$ and R.P. Falcão ${ }^{1}$
${ }^{1}$ Centro de Terapia Celular, Departamento de Clínica Médica, Faculdade de Medicina de Ribeirão Preto, Universidade de São Paulo, Ribeirão Preto, SP, Brasil

${ }^{2}$ Hemocentro de Pernambuco (HEMOPE), Recife, PE, Brasil
Correspondence

R.P. Falcão

Departamento de Clínica Médica

Faculdade de Medicina de

Ribeirão Preto, USP

Av. Bandeirantes, 3900

14049-900 Ribeirão Preto, SP

Brasil

Fax: +55-16-633-1144

E-mail: rpfalcao@fmrp.usp.br

Research supported by FAPESP (No. 98/14247-6) and CNPq (520.786/96-3).

R.T. Calado was the recipient of

a FAPESP fellowship (No. 00/13885-0)

Received May 7, 2003

Accepted September 18, 2003

.......................

\begin{abstract}
The multidrug resistance P-glycoprotein is a transmembrane efflux pump expressed by lymphocytes and is involved in their cytolytic activity. In the present study, we investigated the age-related changes of P-glycoprotein function in normal peripheral blood lymphocytes. Blood samples from 90 normal volunteers (age range, 0 to 86 years) were analyzed. P-glycoprotein function was assessed by the flow cytometric rhodamine 123 assay. P-glycoprotein function was highest in cord blood and progressively declined with age in peripheral blood T CD4+ and CD8+ cells. In contrast, P-glycoprotein function did not vary with age in CD19+ B or CD16+CD56+ natural killer cells. These data suggest that the decline in P-glycoprotein function in T CD4+ and $\mathrm{CD} 8+$ lymphocytes as a function of age may contribute to the decrease in $\mathrm{T}$ cell cytolytic activity with aging.
\end{abstract} Key words - P-glycoprotein - Multidrug resistance

- Lymphocytes

- Rhodamine 123

- Flow cytometry

\section{Introduction}

P-glycoprotein (P-gp), encoded by the $M D R 1$ ( $A B C B 1)$ gene, is an energy-dependent transmembrane efflux pump for a variety of unrelated hydrophobic amphipathic drugs (1) which actively extrudes toxic compounds from the cell cytoplasm through the plasma membrane. P-glycoprotein is expressed by different normal tissues (2). It is found in epithelial cells of the small and large intestine and in the proximal tubules of the kidney, in hepatocytes, pancreas, blood-brain and blood-testis barriers, and in hematopoietic tissue. In the hematopoietic compartment, $\mathrm{P}$-gp is mainly expressed by $\mathrm{T}$, natural killer (NK) and B lymphocytes, as well as stem cells (3-6).

A strong body of evidence suggests that P-gp also plays a role in cytolytic activity and cytokine secretion by lymphocytes (7-10). The blockade of P-gp function by the MRK16 monoclonal antibody inhibits $\mathrm{T}$ cell-mediated cytotoxicity. MRK-16 and UCI2 (monoclonal antibodies directed against Pgp) and other drug-pump inhibitors are able to inhibit the transport of interleukin-2 (IL2), IL-4 and interferon- $\gamma$ in T lymphocytes.

On the other hand, cellular and humoral immunity progressively declines with age (1114). $T$ lymphocytes from elderly individuals present decreased in vitro proliferation in response to antigens and mitogens, as well as an impaired cytotoxic response and abnormal 
cytokine secretion. Since P-gp mediates lymphocyte function (7-10), abnormal P-gp activity with aging has been implicated in the decreased immune function observed in older individuals. Different investigators have addressed this question, but discrepant results have been obtained. Pilarski et al. (15) found that P-gp activity declined with age, while Aggarwal et al. (16) found that P-gp function was higher in the elderly. Until now, this question remains unanswered.

The aim of the present study was to assess age-related changes of P-gp function in normal peripheral blood lymphocytes and bone marrow stem cells by means of the flow cytometric rhodamine 123 (Rh123) efflux assay.

\section{Material and Methods}

Samples

Ten umbilical cord blood samples were collected from full-term normal newborns immediately after delivery. Venous blood samples were collected from 80 healthy volunteers divided into eight age groups: 1 to 11 months $(\mathrm{N}=10), 1$ to 3 years $(\mathrm{N}=10), 4$ to 12 years $(\mathrm{N}=10), 15$ to 18 years $(\mathrm{N}=10), 20$ to 30 years $(\mathrm{N}=10), 35$ to 45 years $(\mathrm{N}=10)$, 50 to 65 years $(\mathrm{N}=10)$, and 70 to 86 years $(\mathrm{N}$ $=10$ ). All volunteers came from the same geographic region (Northeastern Brazil), and samples were collected after informed consent was obtained. This study was approved by the local Ethics Committee.

Peripheral blood mononuclear cells were separated by density gradient centrifugation, washed and resuspended in RPMI 1640 medium (Sigma, St. Louis, MO, USA) supplemented with $5 \%$ fetal calf serum to a final concentration of $5 \times 10^{6}$ cells $/ \mathrm{ml}$.

\section{Rhodamine 123-efflux assay}

P-glycoprotein activity was determined by efflux of Rh123 (Sigma), a fluorescent dye that is a substrate for P-gp, as previously described $(4,17,18)$. Briefly, $200 \mu \mathrm{l}$ of purified cell suspension was incubated with Rh123 (final concentration, $200 \mathrm{ng} / \mathrm{ml}$ ) for $20 \mathrm{~min}$. After washing, cells were incubated in Rh123-free medium in the presence or absence of verapamil (Sigma), a P-gp inhibitor (final concentration, $10 \mu \mathrm{M}$ ), for $1.5 \mathrm{~h}$ at $37^{\circ} \mathrm{C}$. Finally, cells were washed in verapamil-containing RPMI medium and incubated with the respective monoclonal antibodies at $4^{\circ} \mathrm{C}$ in the dark for $20 \mathrm{~min}$. Phycoerythrin (PE)-conjugated anti-CD4 (clone SK3, Becton Dickinson, San Jose, CA, USA), peridinin chlorophyll proteinconjugated anti-CD3 (clone SK7, Becton Dickinson), anti-CD8-PE (clone SK1, Becton Dickinson), anti-CD19-PE (clone 4G7, Becton Dickinson), anti-CD16-PE (antiLeu11c, clone B73.1, Becton Dickinson) and anti-CD56-PE (clone NCAM16.2, Becton Dickinson) antibodies were used. After this period of incubation, cells were washed again and up to 50,000 events were detected and analyzed with a FACScan flow cytometer (Becton Dickinson) equipped with an argon-ion laser with a wavelength setting of $488 \mathrm{~nm}$. The Rh123 efflux index was calculated on the basis of the ratio of mean fluorescence intensity for Rh123 in Rh123+ verapamil/Rh123, according to standard recommendations (19).

The Spearman non-parametric correlation test was employed to assess P-gp function changes as a function of age. In addition, the Kruskal-Wallis non-parametric test followed by Dunn's multiple comparison test was used to determine differences among age groups in cell subsets. $\mathrm{P}<0.05$ was considered to be statistically significant.

\section{Results}

\section{P-glycoprotein function in peripheral blood T cells}

The Rh123 efflux index showed that, in 
T CD3+CD4+ cells, P-gp function was highest in cord blood (median, 2.82, first-third quartiles, 2.55-3.44), markedly decreasing with age (20- to 30-year group, 1.39, 1.34$1.51 ; \mathrm{P}<0.001$ ), and reaching the lowest levels in the 70- to 86-year group (1.13, 1.07-1.18; Spearman $r=-0.8 ; P<0.0001)$, as shown in Figure 1. Even when the cord blood group where P-function is highest, was excluded from analysis, the inverse correlation was still significant $(\mathrm{P}<0.001)$. Likewise, in T CD3+CD8+ cells, P-gp also decreased with age. The highest levels were observed in the cord blood group $(8.14,4.84-$ 10.04), progressively declining to 3.00 (2.14$3.90 ; \mathrm{P}<0.05)$ in the 20- to 30-year group and to $1.83(1.61-1.95 ; \mathrm{P}<0.01)$ in the 70 - to 86-year group (Spearman $\mathrm{r}=-0.42 ; \mathrm{P}<$ 0.0001 ), as illustrated in Figure 2. As observed for CD4+ T cells, the correlation was still significant $(P=0.006)$ for $C D 8+T$ cells when the two younger age groups were excluded from analysis.

\section{P-glycoprotein function in peripheral blood B and NK lymphocytes}

In B CD19+ cells, P-gp activity was low in cord blood (1.51, 1.36-1.68), and did not change significantly with age, the highest median value being detected in the 15 - to 18 year group $(1.75,1.62-1.98$; Figure $3 \mathrm{~A})$. However, these levels were not statistically different from the other age groups (KruskalWallis test, $\mathrm{P}=0.49$ ). Similarly, P-gp function did not change significantly with age in NK CD3-CD16+CD56+ lymphocytes (cord blood, 4.48, 2.50-8.51, and 70- to 86-year group, 4.83, 3.72-5.46; Spearman $\mathrm{r}=0.16$; $\mathrm{P}$ $=0.14)$, as illustrated in Figure 3B.

\section{Discussion}

The MDRl gene-encoded P-gp, involved in the export of substances from the cell, is expressed by different normal tissues, such as the hematopoietic tissue (2). Peripheral blood T, B and NK lymphocytes as well as hematopoietic stem cells are the major hematopoietic cells expressing P-gp, but the glycoprotein plays different physiological roles in these cells (2-10). P-glycoprotein participates in the cell secretion of cytokines and in the cytotoxic function of killer cells (7-10).

In the present study, $\mathrm{P}$-gp function in $\mathrm{T}$ $\mathrm{CD} 3+\mathrm{CD} 4+$ and $\mathrm{CD} 3+\mathrm{CD} 8+$ cells was highest in cord blood and progressively declined
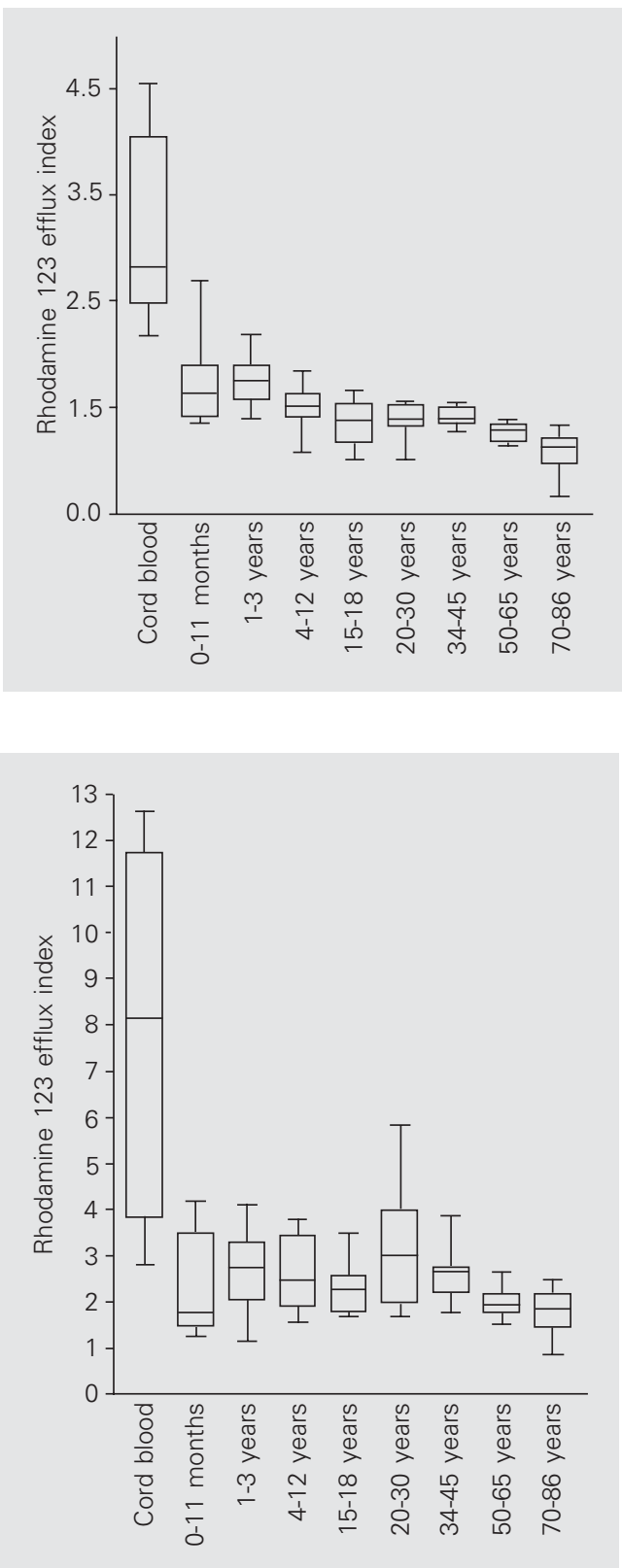

Figure 1. Variation of P-glycoprotein function in T CD4+ lymphocytes with age. P-glycoprotein function is reported as the ratio of rhodamine 123 mean fluorescence in the presence and in the absence of verapamil (rhodamine 123 efflux index). Pglycoprotein functional expression was highest in cord blood, progressively decreasing with age and reaching the lowest levels in the 70- to 86-year group.

Figure 2. Variation of P-glycoprotein function in T CD8+ lymphocytes with age. P-glycoprotein function is reported as the ratio of rhodamine 123 mean fluorescence in the presence and in the absence of verapamil (rhodamine 123 efflux index). Pglycoprotein functional expression was highest in cord blood, progressively decreasing with age, reaching the lowest values in the 70- to 86-year group. 
Figure 3. Variation of P-glycoprotein function in $\mathrm{B} C D 19+(\mathrm{A})$ and NK CD3-CD16+CD56+ (B) lymphocytes with age. P-glycoprotein function is reported as the ratio of rhodamine 123 mean fluorescence in the presence and in the absence of verapamil (rhodamine 123 efflux index). P-glycoprotein activity was low in all age groups and was not influenced by age. with age, reaching the lowest levels in older healthy volunteers; this phenomenon was more evident in T CD3+CD4+ cells. Two different investigators have previously addressed this question with conflicting results. Our findings agree with those of Pilarski et al. (15), who evaluated 5 newborn, 36 young and 5 elderly subjects and found that, in T CD4+ cells, P-gp functional expression declined with age. Moreover, in T CD8+ cells, they found that P-gp function was highest in cord blood, but did not significantly change with age. These data were attributed to the preferential expression of $\mathrm{P}$-gp in naive $\mathrm{T}$ cells, since the proportion of these cells decreases with age (20). In contrast to our findings and those of Pilarski et al. (15), Aggarwal et al. (16) found that P-gp expres-

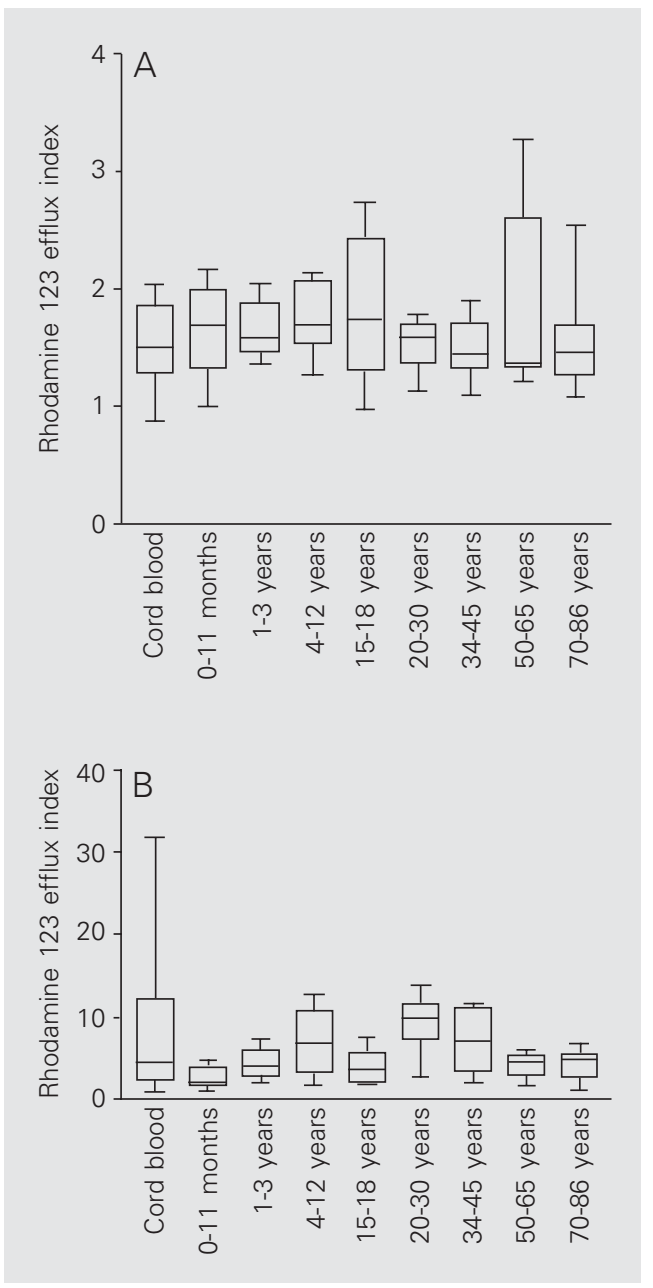

sion in T cells was highest in older individuals. However, they studied 10 young and 10 elderly subjects only, and their findings may have been the result of a skewed population. In a larger number of healthy volunteers (90 individuals) divided into a broader set of age ranges (nine age groups from newborn to 86 years), we definitively demonstrated that, in T cells, $\mathrm{P}$-gp functional expression is highest in cord blood and is progressively reduced with age. The reduction in P-gp activity with age observed in this study paralleled the reduction in $\mathrm{T}$ cell function with aging. These findings could explain, at least in part, the impairment of $\mathrm{T}$ cell function observed in the elderly in comparison to young adults (11-14).

Moreover, we found that P-gp function in B CD19+ cells follows a different pattern as a function of age. It was low throughout all age groups, with a slight increase in the 20- to 30-year group. Our results agree with the single previous observation that $\mathrm{P}-\mathrm{gp}$ function in B CD19+ cells was lower in cord blood and during infancy in comparison to adults (15). In the cited study, the authors speculated that the very high levels of $\mathrm{P}-\mathrm{gp}$ expression in cord blood $\mathrm{T}$ CD4+ and $\mathrm{T}$ CD8+ cells might reflect a transient influence of transplacental maternal factors. However, the low P-gp activity observed in cord blood B CD19+ cells does not support this hypothesis.

Likewise, we found that P-gp activity does not seem to be determined by age in NK lymphocytes, since P-gp functional expression remained high in all age groups. To the best of our knowledge, this was the first time that a correlation between age and P-gp function was done in NK lymphocytes. In this cell subset, P-gp seems to mediate cytotoxicity, since the blockade of P-gp function by different P-gp inhibitors (verapamil, cyclosporine A and PSC833) suppresses NK cell cytotoxic activity in a dose-dependent manner (21). It is interesting to correlate these observations with the finding that NK cell 
activity does not significantly change with age (22). In contrast, P-gp expression is influenced by genetic factors in NK lymphocytes. Hitzl et al. (23) found that the MDRI gene C3435T polymorphism is associated with decreased P-gp function in this cell subset. However, the impact of MDRl gene polymorphisms on $\mathrm{P}$-gp expression in hematopoietic cells is heterogeneous. In a recent study, we failed to demonstrate an asso- ciation between $M D R 1$ gene mutations and P-gp functional expression in bone marrow stem cells (24). Interestingly, in this cell subset, P-gp expression is directly correlated with age (25).

In conclusion, different hematopoietic cell subsets showed different P-gp activity as a function of age, and these changes might be responsible for the specific characteristics of the immune system in the elderly.

\section{References}

1. Higgins $C F$, Callaghan $R$, Linton KJ, Rosemberg MF \& Ford $R C$ (1997). Structure of the multidrug resistance P-glycoprotein. Seminars in Cancer Biology, 8: 135-142.

2. Schinkel AH (1997). The physiological function of drug-transporting P-glycoproteins. Seminars in Cancer Biology, 8: 161-170.

3. Drach D, Zhao S, Drach J, Mahadevia R, Gattringer C, Huber H \& Andreeff M (1992). Subpopulations of normal peripheral blood and bone marrow cells express a functional multidrug resistant phenotype. Blood, 80: 2729-2734.

4. Chaudhary PM, Mechetner EB \& Roninson IB (1992). Expression and activity of the multidrug resistance P-glycoprotein in human peripheral blood lymphocytes. Blood, 80: 2735-2739.

5. Ludescher C, Pall G, Irschick EU \& Gastl G (1998). Differential activity of P-glycoprotein in normal blood lymphocyte subsets. British Journal of Haematology, 101: 722-727.

6. Chaudhary PM \& Roninson IB (1991). Expression and activity of Pglycoprotein, a multidrug efflux pump, in human hematopoietic stem cells. Cell, 66: 85-94.

7. Gupta S, Kim C, Tsuruo T \& Gollapudi S (1992). Preferential expression and activity of multidrug resistance gene 1 product (P-glycoprotein), a functionally active efflux pump, in human CD8+ T cells: a role in cytotoxic effector function. Journal of Clinical Immunology, 12: $451-458$

8. Gupta S \& Gollapudi S (1993). P-glycoprotein (MDR1 gene product) in cells of the immune system: its possible physiologic role and alteration in aging and human immunodeficiency virus-1 (HIV-1) infection. Journal of Clinical Immunology, 13: 289-301.

9. Drach J, Gsur A, Hamilton G et al. (1996). Involvement of P-glycoprotein in transmembrane transport of interleukin-2 (IL-2), IL-4, and interferon- $\gamma$ in normal human T lymphocytes. Blood, 88: 1747-1754.

10. Raghu G, Park SW, Roninson IB \& Mechetner EB (1996). Monoclonal antibodies against P-glycoprotein, an MDR1 gene product, inhibit interleukin-2 release from PHA-activated lymphocytes. Experimental Hematology, 24: 1258-1264.

11. Miller RA (1996). The aging immune system: primer and prospectus. Science, 273: 70-74.

12. Nagel JE, Chopra RK, Chrest FJ, McCoy MT, Schneider EL, Holbrook NJ \& Adler WH (1988). Decreased proliferation, interleukin 2 synthesis, and interleukin 2 receptor expression are accompanied by decreased mRNA expression in phytohemagglutinin-stimulated cells from elderly donors. Journal of Clinical Investigation, 81: 96-109.

13. Fernandes G \& Gupta S (1981). Natural killing and antibody-dependent cytotoxicity by lymphocyte subpopulations in young and aging humans. Journal of Clinical Immunology, 1: 141-148.
14. Gupta $S$ (1989). Membrane signal transduction in T cells in aging humans. Annals of the New York Academy of Sciences, 568: $277-$ 282.

15. Pilarski LM, Paine D, McElhaney JE, Cass CE \& Belch AR (1995). Multidrug transporter P-glycoprotein 170 as a differentiation antigen on normal human lymphocytes and thymocytes. American Journal of Hematology, 49: 328-335.

16. Aggarwal S, Tsuruo T \& Gupta S (1997). Altered expression and function of P-glycoprotein (170 kDa), encoded by the MDR1 gene, in $T$ cell subsets from aging humans. Journal of Clinical Immunology, 17: 448-454.

17. Calado RT, Garcia AB \& Falcão RP (1998). Decreased activity of the multidrug resistance P-glycoprotein in acquired aplastic anaemia: possible pathophysiologic implications. British Journal of Haematology, 102: 1157-1161.

18. Calado RT, Garcia AB, Gallo DAP \& Falcão RP (2002). Reduced function of the multidrug resistance P-glycoprotein in $\mathrm{CD}_{3} 4^{+}$cells of patients with aplastic anaemia. British Journal of Haematology, 118: 320-326.

19. Marie JP, Huet S, Faussat AM et al. (1997). Multicentric evaluation of the MDR phenotype in leukemia. Leukemia, 11: 1086-1094.

20. Falcão RP \& De-Santis GC (1991). Age-associated changes of memory (CD45RO+) and naive (CD45R+) T cells. Brazilian Journal of Medical and Biological Research, 24: 275-279.

21. Klimecki WT, Taylor CW \& Dalton WS (1995). Inhibition of cellmediated cytolysis and P-glycoprotein function in natural killer cells by verapamil isomers and cyclosporine A analogs. Journal of Clinical Immunology, 15: 152-158.

22. Whitman DB (1999). The immunology of aging. Cambridge Scientific Abstracts. http://www.csa.com/hottopics/immune-aging/ overview.html (access date January 28, 2002).

23. Hitzl M, Drescher S, van der Kuip H, Schäffeler E, Fischer J, Schwab M, Eichelbaum M \& Fromm MF (2001). The C3435T mutation in the human MDR1 gene is associated with altered efflux of the Pglycoprotein substrate rhodamine 123 from $\mathrm{CD}^{+} 6^{+}$natural killer cells. Pharmacogenetics, 11: 293-298.

24. Calado RT, Falcão RP, Garcia AB, Gabellini SM, Zago MA \& Franco RF (2002). Influence of functional MDR1 gene polymorphisms on Pglycoprotein activity in CD34+ hematopoietic stem cells. Haematologica, 87: 564-568

25. Calado RT, Machado CG, Carneiro J-J, Garcia AB \& Falcão RP (2003). Age-related changes of P-glycoprotein-mediated rhodamine 123 efflux in normal human bone marrow hematopoietic stem cells. Leukemia, 17: 816-818. 